\title{
Trauma and Dissociation in All This Can Happen
}

\author{
Ross Morin, Connecticut College
}

\begin{abstract}
This article is a close textual reading of Siobhan Davies and David Hinton's experimental film, All This Can Happen, as an exploration of the causes, symptoms, and coping methods associated with posttraumatic stress disorder (PTSD) in returned soldiers. The paper argues that the film repurposes Robert Walser's short story, The Walk, as an autobiographical account of the mental illness that plagued the author later in his life. The paper examines the connections between the narrated text and the onscreen imagery to identify diagnostic criteria of PTSD (as characterized in the American Psychological Association's Diagnostic and Statistical Manual for Mental Disorders, 5th Edition) such as dissociation, panic, depression, psychological and physiological triggers of flashbacks, avoidance behavior, hyper vigilance, and recurrent and intrusive thoughts. The paper concludes with an analysis of the film's split-screen editing technique, arguing that the experimental form of the film places the viewer deeper into the psychology of the narrator and functions to garner greater empathy and understanding of his pain.
\end{abstract}

Keywords: David Hinton, Siobhan Davies, Robert Walser, The Walk short story, DSM-5, PTSD, split-screen editing, trauma, returned soldiers, panic disorder, experimental dance film, found footage, repurposed footage

We open on what appears to be an extreme close shot of melted celluloid, although it may as well be an extreme wide shot of a landscape decimated by nuclear war. The image, unidentifiable and grey, suggests devastation, loss, and an overall breakdown of meaning and symbolism. The sound is desolate, like wind across a desert, joined by garbled radio transmission, evoking post-war annihilation. The shot sets up themes about destruction of film, landscape, even the human mind. Ultimately, the film is about all three.

All This Can Happen, the experimental film by Siobhan Davies and David Hinton, uses found footage and photographs from the early 20th century to (re)envision The Walk, a short story by Robert Walser originally published in 1917. The Walk is a story told through first-person perspective by a writer who goes for a walk across city and countryside, ruminating and making observations about society, culture, and existence. His commentary is witty and articulate, his criticisms are condemning of an 
oppressive society and confessional of his role as a willing member. Through his observations, he is revealed to be a troubled man, depressed, anxious, and even schizophrenic as his ruminations become near-psychological breakdowns of fits of anger or fear. The Walk gives little indication for the cause of the narrator's pain but suggests that modern society has made him ill, that his role as a devalued artist causes him to live in constant shame and rage. While The Walk criticizes society through the lens of the narrator, its film adaptation, All This Can Happen, turns the lens back onto the psychology of the narrator himself. It is a film about a man's disconnect from people, society, and most importantly, from himself.

All This Can Happen is experimental in its use of split screen, frame-by-frame slow motion, and still photograph images. This article will comment on the use of these experimental techniques briefly in its conclusion; this article is primarily focused on the analysis of the psychologies of film's narrator and its author, Robert Walser. This article hypothesizes that Davies and Hinton's adaptation of The Walk was influenced by the life experiences of Walser before and after he wrote the story. Walser served in the Swiss national guard, ${ }^{1}$ published the story in the middle of World War I, and in the early 1930's, was diagnosed with schizophrenia and forced into a psychiatric hospital where he died one winter day when out for a walk. ${ }^{2}$ The film is focused on these links between war, death, and mental illness. While The Walk only makes occasional reference to war, All This Can Happen puts it front and center.

Perhaps Walser's biography served as inspiration for interpreting The Walk not as an expression of Walser's potentially mis-diagnosed schizophrenia but as an expression of posttraumatic stress disorder (PTSD), a diagnosis that did not exist until 1980. Davies and Hinton's film attempts to understand and express empathy for the emotional, psychological, and physiological pain of soldiers suffering from PTSD.

This article will begin with a brief description of posttraumatic stress disorder as defined by the American Psychiatric Association's Diagnostic and Statistical Manual for Mental Disorders, Fifth Edition (DSM-5). ${ }^{3}$ It will then analyze, sequence by sequence, how the film's content and structure is directly motivated by the narrator's disorder in an attempt to create understanding and empathy for his painful experience. Finally, the article will analyze the use of split screen editing in the context of dissociation and detachment, common symptoms of PTSD.

\section{Diagnosis}

Two of the key symptoms of PTSD are the re-experiencing of the trauma and the entering of a dissociative state caused by triggering stimuli. These responses are often painful, recurring, and uncontrollable. The DSM-5 notes how dissociation can last for a long period of time and is triggered by simple events: 
Commonly the individual has recurrent and intrusive recollections of the event [...] Recurrent, involuntary, and intrusive distressing memories of the traumatic event(s) [...] Dissociative reactions (e.g. flashbacks) in which the individual feels or acts as if the traumatic event(s) were recurring [...] The individual may experience dissociative states that last from a few seconds to several hours or even days, during which components of the event are relived and the individual behaves as if the event were occurring at that moment [...] Intense psychological distress [...] or physiological reactivity [...] often occurs when the person is exposed to triggering events that resemble or symbolize an aspect of the traumatic event. ${ }^{4}$

Two common coping behaviors for sufferers of PTSD are denial and avoidance. The DSM-5 notes, "The individual commonly makes deliberate efforts to avoid thoughts, memories, feelings, or talking about the traumatic event [...] and to avoid activities, objects, situations, or people who arouse recollections of it." ${ }^{5}$

Finally, the DSM-5 covers how affective and physiological PTSD symptoms may range from lethargy and depression to hyper vigilance and anxiety. The individual may feel, "detached or estranged from other people or a persistent inability to feel positive emotions [...] Individuals with PTSD may be quick tempered and may even engage in aggressive verbal and/or physical behavior with little or no provocation [...] Individuals with PTSD may be very reactive to unexpected stimuli, displaying a heightened startle response." ${ }^{16}$

All This Can Happen is the story of a man returned from war, existing mostly in a dissociated state, oscillating between terror, joy, and boredom. This article explores the film in the context of the PTSD symptoms of recurrent and intrusive thoughts, denial, hyper vigilance, and dissociation.

\section{Empathy and the Unreliable Narrator}

All This Can Happen allows the audience access to the narrator's mind and heart through a selection of passages from The Walk, through its use of found footage and photographs, and through its editing and sound design. The protagonist of the film, who is also the narrator, tells the story of his walk via voiceover and although he says that he believes that it "actually did happen," 8 many of his claims are dubious. The film, through its selection and omission of text from The Walk, represents a narrator whose observations are exaggerated beyond metaphor, whose emotions rapidly oscillate without motivation, and who slips in and out of first and third person. He comes across as an unreliable narrator; his reports of facts are not to be trusted. But All This Can Happen is not interested in a factual account of the narrator's walk; the film is interested in the emotional and psychological experiences of The Walker. The audience is sutured into the viewpoint of the narrator so they may experience the world as he does, and gain understanding or empathy for his plight. 
Found footage and photographs from the early 20th century are juxtaposed with the voiceover narration. Thus the film visually places the audience into the period when Walser wrote The Walk, the world that Walser (and the WWI soldiers) inhabited. In addition to visual content, the editing and sound design are used to evoke and manifest the emotions that the narrator experiences during his walk. The found footage is frozen, multiplied, split, slowed, and distorted in countless ways to articulate the disjointed and dissociated psyche of the narrator, allowing the audience to perceive the world as he does. Although what "actually happened" during his walk is unknown to the audience, the film provides a significant contextualizing element that does not exist in the book with the opening sequence.

\section{Recurrent and Intrusive Thoughts in the Opening Sequence}

The opening sequence lasts only one and a half minutes, but without it the rest of the film would be an enigma. The opening sequence, unlike the rest of the film, exists outside of the consciousness of the narrator, beyond his grasp as a writer. There is no voiceover narration and no parallel in the original version of The Walk. The sequence is key to the filmmaker's interpretation of the book as a story about PTSD.

PTSD is rooted in a specific causal event or events that affect an individual. The DSM-5 describes the cause as "exposure to actual or threatened death [... by] directly experiencing the traumatic event [or] witnessing, in person, the event(s) as it occurred to others." ${ }^{\prime \prime}$ The opening sequence presents us with a man-presumably the narrator-lying in a hospital bed, shaking uncontrollably, looking across the room in a state of terror. He sees a weak and disabled man who tries to walk but repeatedly falls to the ground. The editing repeats the moment over and over, in slow motion. This moment of pain and weakness, burned into his brain and replayed endlessly, is the representation of his trauma.

In the same sequence, troops march up a hill, a soldier tumbles downward, and another man is unable to get off the ground. The dark soundscape only furthers the sense of Sisyphean futility and dread as the narrator stares on in disbelief, shaking uncontrollably. These images of pain and suffering may represent his first-hand experiences or those that he saw in others. In the diagnosis of PTSD mentioned above, either is essential to trauma.

One key word in the DSM-5's descriptions of PTSD is recurrent. Indeed, the narrator cannot stop the images of pain and suffering. A doctor, unable to help, shakes the narrator's head violently as the images play over and over. Finally, electric current sounds, suggestive of shock treatment, bring the scene to a close. The sequence ends with the image of a screaming man splashing water on his face. He's clean, healthy, and ready to be released. However, in the rest of the film the narrator moves fluidly in and out of dissociative states, suggesting that the hospitalization and treatment was insufficient and even a contributing factor to the illness he develops. 


\section{Denial, Detachment, Distress, and Dissociation}

After the opening sequence, the film switches to the present and introduces a healthier-looking narrator at his writing desk writing about how our "lads are fighting for us." ${ }^{10}$ This visual, like many visuals in the film, is not present in The Walk and as such is entirely a creation of and emphasis by the filmmakers. The film suggests that although the narrator has been released from the hospital, he has not stopped thinking about the war. It consumes him, even as he goes about his work. He admits how the "desire to take a walk" overcomes him and he leaves his "room of phantoms" to hurry into the street. ${ }^{11}$ The subsequent film is about inarticulable and inconceivable pain; most of the insights the audience gains are from what isn't said. The film lets the audience determine the reasons for which he stopped writing, the extent to which he "desired" to be outside, and the manner in which he "hurried" out of his building to the street. ${ }^{12}$ Although not explicit, one could be right to guess that his writing about war and thinking about his friends who died (the "phantoms"), ${ }^{13}$ triggered anxiety and panic, causing him to run outside. In fact, the entire walk itself could be seen as avoidance behavior as mentioned in the DSM-5 above. The Walk is his attempt to repress and deny the trauma. He fails, of course. His dark thoughts recur at inappropriate times and he remains susceptible to triggers of all sorts.

As he steps onto the sunlit streets, he announces that the "all sorrow, all pain and all grey thoughts were as vanished,"14 and he feels that he has successfully escaped his traumatic pain. A beat later, he grows concerned about the heavy thoughts that lie "before me and behind me;" 15 and within seconds, his happy thoughts of children running around darken, saying, "before long, old age will terrify and bridle them." This example of happy thoughts being intruded upon by recurrent dark ideas establishes a cycle that will replay for the narrator throughout the rest of the film. The film, through its omission of original text, is able to condense and thus heighten the sense of oscillation between emotional and affective poles, making the narrator's suffering clear to the audience.

In the next scene, the narrator passes by workers and laborers and feels "honestly ashamed"16 for being out for a walk. He runs into an old friend from the militia who accuses him of being out during working hours. He feels shame not simply because he's walking during work hours, but because he's out for a walk at all. He is reminded of his fallen brothers who are unable to walk and feels a sort of "survivor guilt," adding to his layers of distress.

The scene also introduces a theme of how loud noises cause intense distress for the narrator. He exhibits irritability and an exaggerated startle response as described by the DSM-5, and combined with his guilt, he is sent spiraling towards paranoia. The film shows visuals of countless eyes spying on him, and just as it seems he may have a complete emotional breakdown, he fends it off through denial. He claims that he 
doesn't feel the "least annoyance for having been found out. For that would have been silly."17 Through his self-deception, the film reveals his unreliability-not because he is lying to the audience, but because he is lying to himself.

Within a moment, and without clear reason, he's happy again and begins a new emotional cycle. He claims to love everything he sees with a "fiery love." ${ }^{18}$ The visuals display colorful photography and are accompanied by the sound of light whistling. His next emotional descent begins as talks about the happy children playing in the road. Soon the film is flooded with images of traffic, and he remarks how easily the children could be "crushed to a pulp." ${ }^{19}$ The intrusive and recurrent thoughts of violence are fleshed out by the visuals, climaxing in a shot of a man preparing a child's coffin.

Throughout the film, the visual imagery reflects the subconscious and repressed emotions of the narrator. They show the subtext-what he cannot (and will not) articulate-and provide insight to the narrator's pain and complicated conceptualization of his experience. The visuals are essential to connecting the audience to the experience of the narrator. For example, in the scene after the child's coffin is revealed, there is a rare moment of backstory in which the narrator mentions coming "to this region out of cold, forlorn and narrow circumstances. Inwardly sick." ${ }^{20}$ The narrator never says that the military is the cause of his pain-he's too far along in his denial and repression. Rather, the accompanying visuals of a man in a hospital and a disabled soldier provide the details.

The narrator's first sustained interaction with another human occurs in the bookshop, where he asks for a book that is both popular and well-written. The visuals suggest that the bookseller hands him a copy of Alice's Adventures in Wonderland (another book about a person in a dream state out for a walk). The narrator says thank you "cold-bloodedly," 21 and as he leaves, the bookseller yells at him and calls him "uncultivated and ignorant." ${ }^{22}$ There is nothing in the narration to motivate such a response by the bookseller, so the audience is left to speculate. At first, it appears that the bookseller is to blame-he is overly "cultured" and condescending — but by this point in the film, the audience knows that narrator possesses an unpredictable and agitated affect, and one that he seems unaware of. His cold-blooded "thank you" hints that he may have been rude to the bookseller throughout their interaction, questioning the bookseller's intelligence. It is just as likely, maybe even more so, that the narrator is the one to blame. As mentioned above, DSM-5 indicates that people with PTSD may engage in "aggressive verbal and/or physical behavior with little or no provocation," ${ }^{23}$ and this scene could be read in these terms, demonstrating it through the narrator's cold, scrutinizing, and condescending treatment of the bookseller.

Soon after, the narrator gets caught up in the newspapers, noting phrases like "flank attack," ${ }^{24}$ and compares the art of war to the art of writing. He says he's thinking about how sometimes a "book must die and the writer despair of it all,"25 suggesting that 
he's actually thinking about soldiers dying. The details in the narration are present in The Walk, but the film uses these small remarks as jumping off points to explore its thesis about PTSD in full force. The visuals show soldiers marching, explosions, and devastation-conjuring up the opening images of the film. Before long, the visuals show dead men in trenches, as the narrator grows overwhelmed. As the moment reaches a climax, the visuals switch over to shots of grass and nature as the narrator calms himself down. The drama in the film becomes clear: how much longer will the narrator be able to fend off the intrusive imagery? How much longer will his repression and denial hold up before he is beaten to a pulp, forced to surrender to madness and pain.

He remains peaceful for a short while but soon admits that, "When I'm out walking, many notions, flashes of light, and lightning flashes, intrude and interrupt." ${ }^{26}$ The visuals and sound design suggest that the flashes are distressing-lightning cracks across the screen, the audio becomes warbling screeches, and the images turn into a garbled mess of symbols and darkness and end with a solar eclipse. The PTSD symptoms have overpowered him and he has entered a state of total dissociation that leads him to a direct encounter with the manifestation of his trauma: Tomzack. Tomzack, "an enormity, a monster, who almost completely darkened my bright and shiny road [...] Beside him I felt like a dwarf or a poor weak child. Oh I knew who he was [...] he had to live without love and without human joy [...] He died every instant and yet he could not die." ${ }^{27}$ This is the first moment of great despair that he faces. He feels complete terror and helplessness in his confrontation with inarticulable trauma and pain, manifested in a timeless, dark, inhuman giant. The intrusive thoughts of war and death are as endless and undying as Tomzack. He manages to elude Tomzack, but knows that he will see him again.

Snapping out of his dissociative state, he finds himself in a beautiful and quiet forest, and he thinks of sleep. He has an overall feeling of gratitude for the world that breaks "powerfully out of my soul." ${ }^{28}$ He thinks of making love on the forest floor, but his thoughts turn quickly to what it must be like to die there. Thoughts of suicide are in line with the DSM-5 that notes, "PTSD is associated with suicidal ideation." ${ }^{29} \mathrm{He}$ ends with the thought, "To have a small, quiet grave in the forest would be lovely." ${ }^{30}$

The cycle goes on like this: a moment of joy is followed by intrusive thoughts of fear and violence, eventually culminating in thoughts of death. A pleasant stray dog provides the narrator the opportunity to berate and abuse, a young girl's singing turns into thoughts of dying with a smile, a schoolhouse triggers thoughts of being beaten and thrashed, a pleasant lunch turns into panic attack of terror and disgust where he is forced to eat an excess of meat, and a trip to the tailor leads to a shouting match in which the narrator runs away in shame. 
He speaks with great respect to a taxman as he begs for a break for being so poor. He claims that he is misunderstood and disconnected from the people and the world around him and his rant sends him into an intense state of dissociation. He even describes his panicked state in third person. His words echo the DSM-5; "he will again and again be confused and startled by curious impressions and bewitchings of spirit power. He has the feeling that he must sink all of a sudden into the earth [...] an abyss has opened [...] and he must ask himself 'Where am I?'"31 The visuals turn blurry and chaotic; he is consumed with fear. "Earth and Heaven suddenly stream together and collide into a flashing, shimmering ... imagery, ${ }^{232}$ he says as the visuals and sounds simulate explosions and fireworks. The images and celluloid melt as if caught in a projector, and the entire film seems to break down. In this moment, finally, the narrator does too. He continues to try to repress and deny, as has worked before, but this time is different. He now refers to himself in third person, truly dissociated: "he laboriously tries to retain his normal state of mind. He succeeds and he walks on." 33

The narrator then hopes he has returned to normal, but in fact, he has changed. He returns to the world uncertain about his reality, and although he claims to believe that everything he's described "actually did happen," 34 his use of third-person narration suggests he's not in the position to judge. He finds himself back with the taxman and is told that they will consider cutting him a tax break after all. He is overjoyed, "raptures of freedom seized me and carried me away" 35 back onto the streets. While this may seem like just another cycle of joy and terror, he has actually started to break free.

There are three remaining significant events that demonstrate a new cycle, and perhaps even a path to recovery. The first event comes as he passes a train filled with travelling soldiers. He identifies with them, and remarks on how the civilians cheer for them. He does not avoid or run from this trigger; in fact, he is filled with positive emotions. His world becomes "a thousand times more beautiful [...] All grief, all human disappointment, all evil, all pain seemed to vanish." ${ }^{36}$ The film repeats imagery of hands allowing birds to fly away-letting go. Indeed, the final moments of the film are about just that.

He continues in his state of joy and experiences a new state of re-association, claiming, "I walked as in an inward world. Everything outside me became a dream. I was no longer myself. I was another. And yet it was on this account that I became properly myself... In the sweet light of love I realized... Perhaps the inward self is the only self that really exists." ${ }^{37}$ The images reveal children playing happily and, unlike every other occasion in the film, his thoughts are not intruded by images of death. His existential revelation is that he exists even if he can't trust the world around him. He finds a sort of self-love and unconditional acceptance for the first time. 
In the evening, he reaches a forest by the lake, and it is here that he begins the process of mourning. In Judith Herman's Trauma and Recovery, she describes mourning as essential to recovery: "the descent into mourning is at once the most necessary and most dreaded task in this stage of recovery." ${ }^{138}$ It is essential that PTSD sufferers grieve for the pain they have experienced, witnessed, or caused. The narrator reflects on loss, and soon the visuals grow violent and angry as a face conveys states of narrator's internal pain. He becomes overwhelmed with guilt, perhaps for the atrocities he committed or witnessed during the war. As he wonders how he was so cruel, he grieves for his own weakness, stating, "past life opened to me and I was seized by astonishment with my countless frailties." ${ }^{39}$ As he reflects upon death and destruction one final time, he picks flowers that surround him. "Did I pick flowers to lay them upon my sorrow?" 40 he asks himself, knowingly. The flowers are, of course, signs that he is grieving and mourning his past. He may not be recovered, but he is starting to recover. He lets the flowers fall to the ground and walks home in the darkness.

\section{The Divided Canvas}

The most remarkable formal device in the film is its use of split screen and black lines to separate onscreen images. The purpose of conventional split screen technique is to provide multiple perspectives of a particular moment in time; to allow the audience to see simultaneity in a way alternative to parallel editing or cross-cutting. Consider the split screen editing of Brian De Palma in his early films like Dressed to Kill. ${ }^{41} \mathrm{His}$ split screen technique serves to create a more cohesive experience of a particular moment from two perspectives, to enhance the viewer's knowledge of the diegetic drama.

Split screen or multiple projection technique has its place in the avant-garde as well. Andy Warhol's Chelsea Girls, ${ }^{42}$ for example, requires that two projectors screen unique scenarios at the same time, allowing the audience the choice to choose one story, or one moment from a story, over the other. In this case, the split screen creates entirely new meaning as the images, sounds, and dialogue interact and juxtapose with one another. Barbara Rubin's Christmas on Earth ${ }^{43}$ simultaneously projects graphic sex acts on two projectors, one inside the other, as if the projectors themselves are engaging in intercourse. In Rubin's film as well, the audience creates new meaning as the images interact onscreen.

All This Can Happen, like Warhol and Rubin's work, uses split screen to allow for the construction of multiple meanings without regard for diegetic simultaneity. That is to say, since De Palma limits his use of split screen technique to literal diegetic simultaneity, he uses editing to enrich a single idea; but Davies and Hinton use their split screen so that as one image is added to another, multiple ideas are created all at once. Even more, Davies and Hinton are not limited to only two simultaneous images; often they use far more. 
Digital editing software refers to the edited timeline as a temporal "canvas." If the comparison to a painting is to be taken literally, the cinematic canvas chosen here is a severely restricted one. The canvas in the editing room exists temporally, and the only "paint" the editor may use is footage that has already been shot. The editor-as-painter does not create images; she controls how long an image is shown before moving on another. With the exception of occasional dissolves or superimpositions, rarely is the editor's canvas a place to combine or alter images. The timeline canvas doesn't spatially construct ideas; it does so temporally. All This Can Happen turns the editor's temporal canvas into a painter's spatial canvas, uniquely placing multiple images on the screen at the same time. The film uses the canvas not just for montage, but also, significantly, for collage and decoupage.

Between the multiple images onscreen lie many black separating lines; the empty canvas beneath. The film's black lines construct a new language of articulation and are aesthetically and philosophically meaningful. The split screen of multiple images frees the film for on-screen choreography that otherwise is only available across the edit point. Traditional editing allows for collisions and connections of shapes, movements, colors, brightness, etc., but only across the temporal cut point. All This Can Happen uses the black lines and split screen so that connections and collisions may be made across the screen-canvas itself. Images may respond to and play off of one another at the same time. The overall meaning of a particular moment is constructed without preferential regard for any one image, but instead on how the images come together as a whole.

Of course, the conflicting and complementary images seen onscreen at the same time are manifestations of the conflicted internal experience of the narrator. $\mathrm{He}$, too, has trouble telling which image is "real" or primary. And so the film places the audience into the psychological perspective of the narrator-we struggle as he struggles. We find meaning as he does. We feel alone, disconnected, confused, scared, as he does. This is a film about empathy, and the visuals are essential to this process. The narrator does his best to communicate his experience to us, and the editing fills in the gaps. The audience hears his story and experiences, and viscerally feels, through the editing, his tortured state of mind.

All This Can Happen is striking in its ability to make visible the psychology of the narrator through the juxtaposition of visuals across the edit points, between visuals on the same screen, and against the sound design and carefully chosen text from The Walk. The film shows visuals that depict colors and context of the narration, but it also reveals images that are not in the narration at all. The film is about the subtext, gaps, about all that exists between the lines. The black lines and visible canvas are nonspace, the absence of articulable meaning. They are denial, repression, amnesia-the forbidden subconscious made visible, a manifestation of dissociation and disconnection. 
Before PTSD was named, those who suffered it, like Walser's narrator (if not Walser himself) and $40 \%$ of soldiers returning from WWI, ${ }^{44}$ were seen as broken men, physically damaged and weak, and left to fend for themselves or hidden away in institutions-alone and misunderstood, unknown to the world and foreign to themselves. Decades later, PTSD is recognized as a treatable ailment due to advancements in cognitive behavioral therapy and medication; it has a name and it is visible to us. In All This Can Happen, Davies and Hinton rely on our contemporary and more widespread understanding of the disorder as they use a unique combination of found footage, narration, sound design, and across-the-canvas editing to provide insight and empathy into the body and mind of a tormented, fragmented, divided soul. I suspect that Robert Walser, alone and psychologically broken in his later years, would have appreciated such empathy.

\section{Biography}

Ross Morin is an independent filmmaker and assistant professor of Film Studies at Connecticut College in New London, Connecticut, where he teaches filmmaking and heads the film production curriculum. His most recent films, $A$ Wheel out of Kilter and Ad Noctum, have screened nationally and internationally and won multiple awards. He is the co-founder of Kiltered Productions. Morin received his BA in Film Studies and Psychology from Connecticut College in 2005 where he graduated Phi Beta Kappa. He received his MFA in Film and Video Production from Ohio University in 2008 where he graduated Phi Kappa Phi.

Email: rwmor@conncoll.edu

\section{Notes}

${ }^{1}$ Lerner, Ben, "Robert Walser's Disappearing Acts."

${ }^{2}$ Kunkel, Benjamin, "Still Small Voice: The Fiction of Robert Walser."

3 American Psychiatric Association, Diagnostic and Statistical Manual of Mental Disorders, Fifth Edition.

${ }^{4}$ Ibid., 272.

${ }^{5}$ Ibid., 273.

${ }^{6}$ Ibid., 274.

${ }^{7}$ Walser, The Walk. 
${ }^{8}$ All This Can Happen (2012).37:04.Dir. Siobhan Davies, David Hinton. 37:04.

9 American Psychiatric Association, Diagnostic and Statistical Manual of Mental Disorders, Fifth Edition, 271.

${ }^{10}$ All This Can Happen (2012). Dir. Siobhan Davies, David Hinton. 1:58.

${ }^{11}$ Ibid., 02:20.

12 Ibid., 02:24.

13 Ibid., 02:20.

${ }^{14}$ Ibid., 02:38.

15 Ibid., 02:50.

${ }^{16}$ Ibid., 03:44.

17 lbid., 04:25.

18 lbid., 04:40.

19 Ibid., 05:10.

20 Ibid., 06:24.

${ }^{21}$ Ibid., 09:50.

22 Ibid., 09:57.

23 American Psychiatric Association, Diagnostic and Statistical Manual of Mental Disorders, Fifth Edition, 271.

${ }^{24}$ All This Can Happen (2012). Dir. Siobhan Davies, David Hinton. 11:02.

25 Ibid., 11:41.

${ }^{26}$ Ibid., 13:00.

${ }^{27}$ Ibid., 14:35.

${ }^{28}$ Ibid., 14:35.

29 American Psychiatric Association, Diagnostic and Statistical Manual of Mental Disorders, Fifth Edition, 280.

${ }^{30}$ All This Can Happen (2012). Dir. Siobhan Davies, David Hinton. 19:18.

${ }^{31}$ Ibid., 35:50.

32 Ibid., 36:17.

33 Ibid., 36:34.

${ }^{34}$ Ibid., 37:04

35 Ibid., 37:36.

${ }^{36}$ Ibid., 38:43.

${ }^{37}$ Ibid., 40:22.

${ }^{38}$ Herman, Trauma and Recovery, 188.

${ }^{39}$ All This Can Happen (2012). Dir. Siobhan Davies, David Hinton. 43:58

40 Ibid., 46:55

${ }^{41}$ Dressed to Kill (1980). Dir. Brian De Palma.

${ }^{42}$ Chelsea Girls (1966). Dir. Andy Warhol.

${ }^{43}$ Christmas on Earth. Dir. Barbara Rubin.

${ }^{44}$ Herman, Trauma and Recovery, 20. 


\section{References}

All This Can Happen. Dir. Siobhan Davies and David Hinton. UK, 2012. Digital Video.

American Psychiatric Association. Diagnostic and Statistical Manual of Mental Disorders, Fifth Edition. Arlington, VA: American Psychiatric Association, 2013.

Chelsea Girls (1966). Dir. Andy Warhol. USA: Raro, 2003. DVD.

Christmas on Earth. Dir. Barbara Rubin. USA: 1963. Film.

Dressed to Kill (1980). Dir. Brian De Palma. USA: MGM, 2011. DVD.

Herman, Judith. Trauma and Recovery. New York: Basic Books, 1997.

Kunkel, Benjamin. "Still Small Voice: The Fiction of Robert Walser." The New Yorker. Posted 6 Aug. 2007. http://www.newyorker.com/magazine/2007/08/06/still-smallvoice

Lerner, Ben. "Robert Walser's Disappearing Acts." The New Yorker. Posted 3 Sep. 2013. http://www.newyorker.com/books/page-turner/robert-walsers-disappearing-acts

Walser, Robert. The Walk. Trans. Susan Bernofsky. New York: New Directions Publishing, 2012. 